\title{
Definitions and drivers of relapse in patients with schizophrenia: a systematic literature review
}

José M Olivares ${ }^{1 *}$, Jan Sermon ${ }^{2}$, Michiel Hemels ${ }^{3}$ and Andreas Schreiner ${ }^{4}$

\begin{abstract}
Relapse in patients with schizophrenia has devastating repercussions, including worsening symptoms, impaired functioning, cognitive deterioration and reduced quality of life. This progressive decline exacerbates the burden of illness on patients and their families. Relapse prevention is identified as a key therapeutic aim; however, the absence of widely accepted relapse definition criteria considerably hampers achieving this goal. We conducted a literature review in order to investigate the reporting of relapses and the validity of hospitalization as a proxy for relapse in patients with schizophrenia. The primary aim was to assess the range and validity of methods used to define relapse in observational or naturalistic settings. The secondary aim was to capture information on factors that predicted or influenced the risk of relapse. A structured search of the PubMed database identified articles that discussed relapse, and hospitalization as a proxy of relapse, in patients with schizophrenia. National and international guidelines were also reviewed. Of the 150 publications and guidelines identified, 87 defined relapse and $62 \%$ of these discussed hospitalization. Where hospitalization was discussed, this was as a proxy for, or a component of, relapse in the majority of cases. However, hospitalization duration and type varied and were not always well defined. Scales were used to define relapse in 53 instances; 10 different scales were used and multiple scales often appeared within the same definition. There were 95 references to factors that may drive relapse, including non-adherence to antipsychotic medication (21/95), stress/depression (11/95) and substance abuse (9/95). Twenty-five publications discussed the potential of antipsychotic therapy to reduce relapse rates-continuous antipsychotic therapy was associated with reduced frequency and duration of hospitalization. Non-pharmacological interventions, such as psychoeducation and cognitive behavioural therapy, were also commonly reported as factors that may reduce relapse. In conclusion, this review identified numerous factors used to define relapse. Hospitalization was the factor most frequently used and represents a useful proxy for relapse when reporting in a naturalistic setting. Several factors were reported to increase the risk of relapse, and observation of these may aid the identification of at-risk patients.
\end{abstract}

Keywords: Relapse, Hospitalization, Schizophrenia, Definition, Adherence, Drivers

\section{Introduction}

Schizophrenia is a highly prevalent disorder affecting approximately $1 \%$ of the world's population [1]. Patients with schizophrenia often require antipsychotic medication throughout their lifetime. With correct management, many patients can achieve symptomatic remission [2] as defined, for example, by the Andreasen remission criteria [3]. However, relapses are a highly prevalent component of the disease course $[4,5]$. Schizophrenia is

\footnotetext{
*Correspondence: jose.manuel.olivares@gmail.com

${ }^{1}$ Department of Psychiatry, Hospital Meixoeiro, Complejo Hospitalario

Universitario de Vigo, Vigo 36200, Spain

Full list of author information is available at the end of the article
}

a significant burden, for both patients and families. The clinical deterioration associated with each subsequent relapse only serves to exacerbate this. For patients, relapse can have devastating repercussions such as worsening of symptoms, progressive cognitive deterioration, impaired functioning and reduced quality of life [6-9]. Furthermore, families are affected by the emotional stress and financial burden of living with and caring for a patient with schizophrenia $[10,11]$. To minimize the burden on the patient and family, it is vital that periods of effective symptom control are extended for as long as possible.

\section{Biomed Central}


International guidelines identify relapse prevention as a key therapeutic aim [4-6]; however, there are currently no established criteria by which to define relapse, and our current understanding of relapse may not be sufficient to combat this problem effectively $[6,7,12,13]$.

We conducted a structured literature search to investigate the reporting of relapse and the validity of hospitalization as a proxy for relapse in patients with schizophrenia. Additionally, the factors that may be used to predict a relapse and those factors associated with increased or decreased risk of relapse were also investigated.

\section{Methods}

\section{PubMed search and literature review}

A structured search of the National Center for Biotechnology Information (NCBI) PubMed database was performed to identify articles published from 1 January 2000 to 1 May 2010 that discussed relapse, and hospitalization as a proxy for relapse, in patients with schizophrenia. The search term 'Schizophrenia [Title/Abstract] AND ((Relapse[Title/Abstract]) OR (Hospitalization [Title/Abstract]))' and limits (Humans, Clinical Trial, Meta-Analysis, Review, Classical Article, Clinical Trial, Phase IV, Comparative Study, Congresses, Controlled Clinical Trial, Corrected and Republished Article, Evaluation Studies, Government Publications, Journal Article, Multicenter Study, Published Erratum, English, French, German, Italian, Spanish) were used to identify relevant literature from the database. The latest national (France, Spain, Germany, Italy and the UK) and international (World Federation of Societies of Biological Psychiatry (WFSBP); American Psychiatric Association (APA)) guidelines were also reviewed. The primary objective of this literature search was to determine whether specific criteria have been used to define relapse in observational and naturalistic settings. The secondary aim was to identify possible factors that may drive or reduce relapse.

Randomized clinical trials (RCTs) represent highly controlled situations in which patients are required to meet stringent inclusion criteria. Furthermore, subjects are frequently randomized to a fixed medication dose, without provision for dose optimization to meet individual requirements, which may likely have an impact on patient outcomes. Patients are closely monitored in RCTs, and specific relapse definitions are imposed for consistency across study centres. Hence, RCTs are less informative in regard to routine definitions of relapse used in clinical practice and to factors associated with relapse in unselected clinical populations. Therefore, data from primary publications of randomized, placebocontrolled clinical trials of pharmacological agents were excluded from this literature search.

\section{Abstract review}

Identified abstracts were excluded if they were not relevant to one of the four domains:

1. Definition of relapse.

2. Factors that may predict, drive or reduce relapse.

3. Duration and frequency of relapse.

4. Cost and resource use associated with relapse.

Guidelines were reviewed using the same criteria as the abstracts identified in the PubMed search. Following this review, the selection of literature included $206 \mathrm{ab}$ stracts and five guidelines.

Publications discussing the definition of relapse and factors that may predict, drive or reduce relapse are reviewed here. Those discussing the duration and frequency of relapse or associated cost and resource are reviewed elsewhere.

\section{Full article review}

Following abstract review, each corresponding full article was reviewed and excluded if not relevant to one of the four domains above. Following this review stage, the selection of literature included 156 journal papers and five guidelines. A final review of the literature was conducted. During this final review, the authors excluded those papers describing cost-effectiveness modelling studies that constituted secondary research as accurate interpretation and evaluation of such papers require an indepth analysis of the methodologies and assumptions used, which was deemed to be beyond the scope of the current review.

The final literature selection included 145 journal manuscripts and five guidelines from three organisations (APA [6,14], National Institute for Clinical Excellence (NICE) [4] and WFSBP [2,5]). Figure 1 details the full literature search process.

\section{Results}

\section{Definitions of relapse}

Of the final selection of literature, 87 manuscripts included a definition of relapse. None of the identified guidelines defined relapse. Figure 2 describes the factors used alone or in combination to define relapse. Hospitalization was the most widely used factor as a proxy for relapse or as a component of the definition.

\section{Hospitalization}

'Hospitalization' appeared in 54\% (47/87) of the publications that defined relapse, 62\% (54/87) if grouped with 'exacerbation of symptoms leading to hospitalization'. In these 54 publications, hospitalization or exacerbation of symptoms leading to hospitalization was discussed in 56 separate instances. In the majority $(55 \%, 31 / 56)$ of cases, 


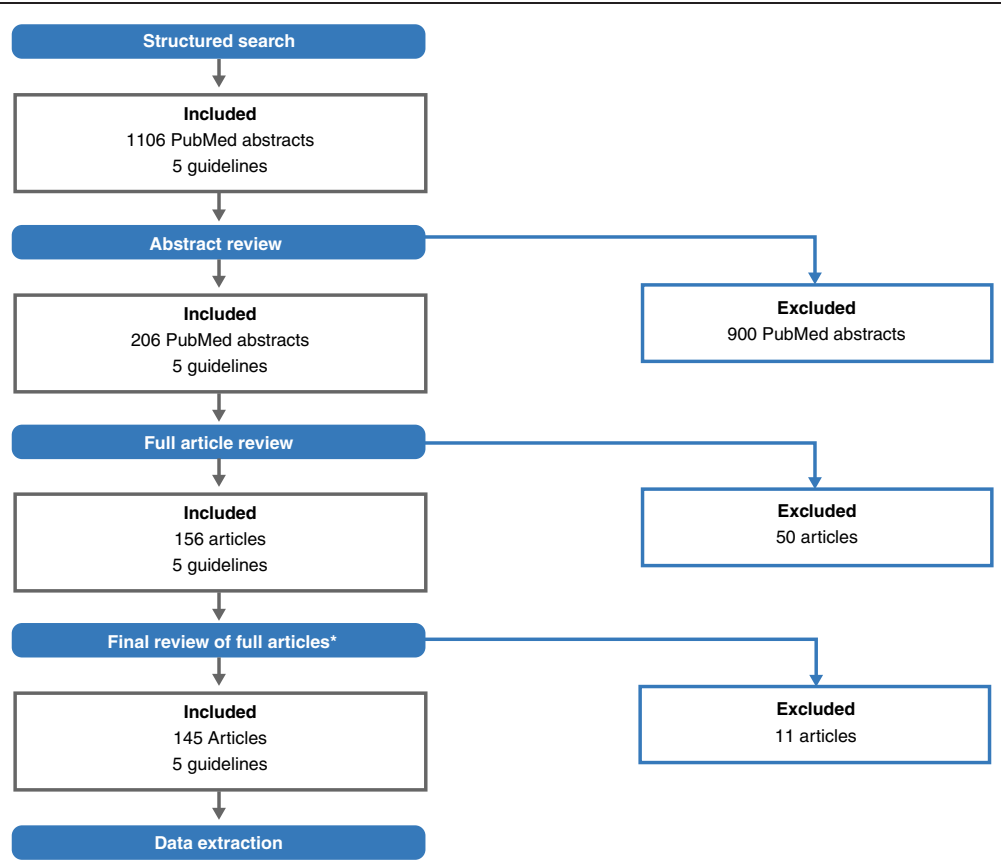

Figure 1 Literature search process. The asterisk denotes that the final review process is described in detail in the main body of the text.

hospitalization was used as a direct proxy for relapse or as a component of a relapse definition. In the remainder $(45 \%, 25 / 56)$, hospitalization was discussed independently or without reference to relapse (Table 1). The majority of publications did not define the length of the hospitalization or the type of hospitalization-generic terms of 'hospitalization' and 'psychiatric hospitalization' were predominantly used. Two publications, published by the same authors, defined hospitalization as ' $36 \mathrm{~h}$ of full hospitalization or a 5-day partial hospitalization due to an exacerbation of acute psychotic symptoms'. However, the difference between 'partial' and 'full' hospitalization was not defined in these publications $[15,16]$.

\section{Scales}

There were 53 instances of a scale being used to define relapse; however, multiple scales often appeared within the same definition. Ten different scales were used to define relapse (Figure 2), including the Positive and Negative Syndrome Scale (PANSS), Clinical Global Impression (CGI) scale (including the CGI-Severity, CGI-Schizophrenia and CGI-Change subscales), Brief Psychiatric Rating Scale (BPRS) and Global Assessment of Functioning (GAF) scale, the most frequently cited being PANSS and CGI. Generally, the scales used to define relapse assessed symptom severity and in particular the positive symptoms of schizophrenia.

There was considerable variation between studies in the use of each scale, in terms of the thresholds applied, and subscales used within the relapse criteria. Among the 18 instances of using the PANSS to define relapse, thresholds included an overall increase in the scale $[7,60,61]$, an increase in the score from baseline $[17,18]$ and recording of a score $>4$ for certain individual PANSS items [62-64]. There was wide variation between studies when using the CGI scale, since many different subscales and thresholds were proposed to define relapse. CGISeverity (CGI-S) was the most commonly cited subscale, with CGI-schizophrenia (CGI-SCH) and CGI-Change (CGI-C) also frequently used. However, the threshold for relapse was broadly similar regardless of the CGI subscale used-with an overall increase (or increase in a single factor) to a score of 6 or 7 being the most frequent measure $[18,19,60,65,66]$.

\section{Other definitions}

Sixteen per cent $(14 / 87)$ of publications defined relapse as a change in behavioural patterns towards more violent or self-destructive ideation or tendencies. Exacerbation or re-emergence of symptoms was the fourth most common component of definitions identified in the literature search, second if combined with those exacerbations that led to hospitalization.

\section{Factors that may increase or decrease the risk of relapse}

Ninety-four journal articles and five guidelines discussed the various factors that may drive or reduce relapse rates in patients with schizophrenia. 


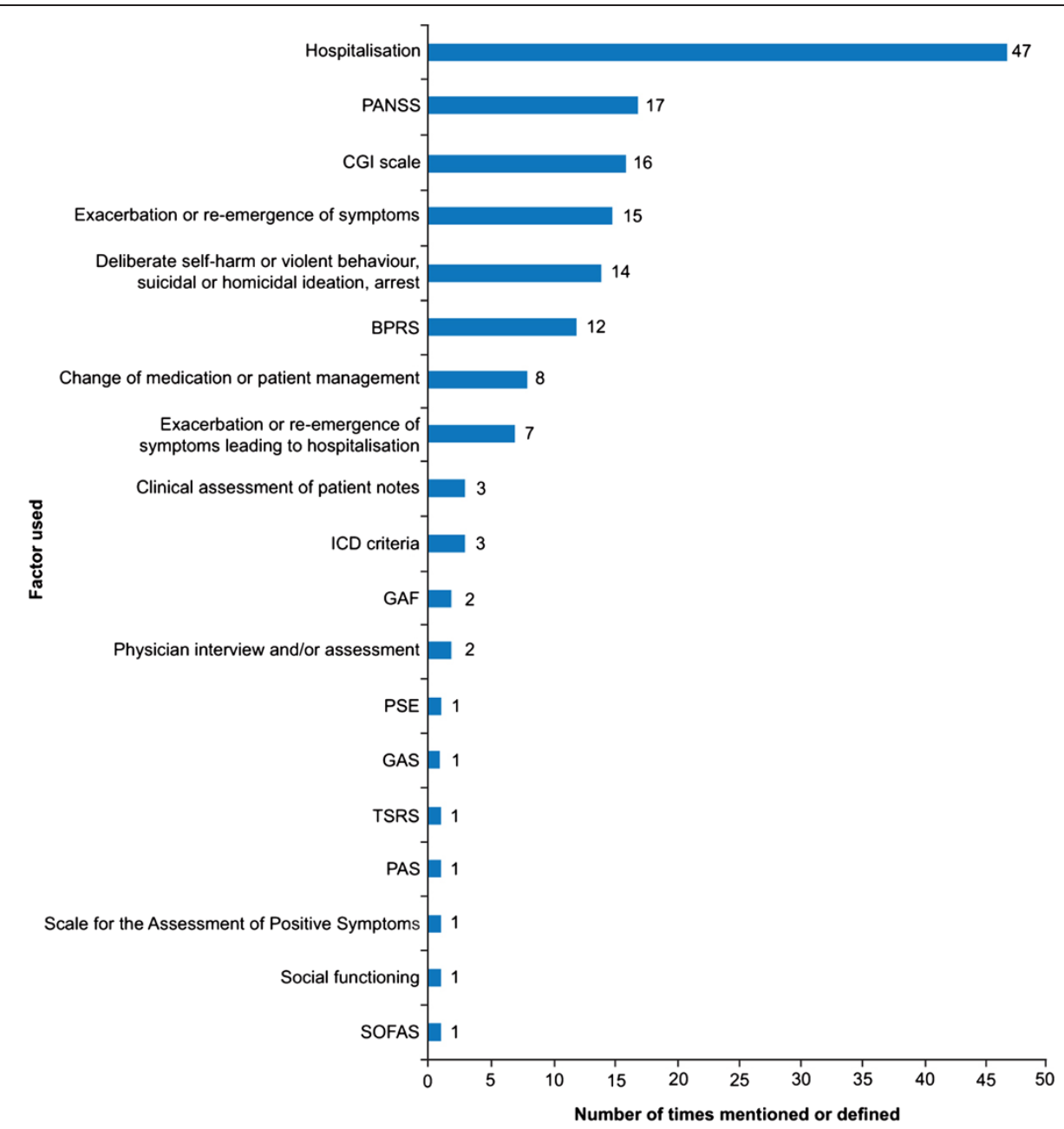

Figure 2 Reported components of the definition for relapse. Hospitalization [11,15-59]; Positive and Negative Syndrome Scale (PANSS) [7,15,17,18,60-72]; Clinical Global Impression (CGI) scale [17,18,26,30,52,57,60-62,65,66,68,71,73,74]; exacerbation/re-emergence of symptoms $[7,27,29,34,38,43,63,67,75-81]$; deliberate self-harm or violent behaviour, suicidal or homicidal ideation, arrest $[18,23,27,43,49,50,57,65,66,71,74,82-84]$; Brief Psychiatric Rating Scale (BPRS) [28,43,71,76,84-91]; change of medication or patient management $[18,27,38,41,56,66,75,92]$; exacerbation/ re-emergence of symptoms leading to hospitalization [20,66,92-96]; clinical assessment of patient notes [38,57,88]; International Classification of Diseases (ICD) criteria [70,89,97]; Global Assessment of Functioning (GAF) [64,72]; physician interview and/or assessment [86,98]; Present State Examination (PSE) [84]; Global Assessment Scale (GAS) [84]; Target Symptoms Ratings Scale (TSRS) [76]; Psychiatric Assessment Scale (PAS) [99]; scale for the assessment of positive symptoms [86]; social functioning [75]; Social and Occupational Functioning Assessment Scale (SOFAS) [60].

\section{Factors that may drive relapse}

There were 95 references to factors that may drive relapse (Figure 3), with non-adherence to antipsychotic medication the most frequently reported factor. For example, in a study of first-episode patients, medication non-adherence was observed in $70 \%$ of patients with relapse, compared with only $25 \%$ of those without relapse, at 1-year follow-up $\left(\chi^{2}=11.2, p=0.001\right)$ [85]. Furthermore, in patients with recently diagnosed ( $\leq 2$ years) schizophrenia, a 69\% relapse rate was observed in patients non-adherent to oral or depot antipsychotic therapy compared with a rate of $18 \%$ in adherent patients $\left(\chi^{2}=12.66, p<0.001\right)[20]$.
Patient-specific, lifestyle and disease-related factors associated with increased rates of relapse were also identified in the search (Figure 3). Stress/depression and substance abuse were the second and third most frequently reported factors associated with relapse. In a retrospective cohort study, depression (adjusted hazard ratio $(\mathrm{AHR})=1.44 ; 95 \% \mathrm{CI}=1.05,1.98 ; p<0.05)$ and substance abuse $(\mathrm{AHR}=1.80 ; 95 \% \mathrm{CI}=1.32,2.47$; $p<0.05)$ were significantly associated with an increased risk of psychiatric hospitalizations [97].

There were 46 instances where treatment-related factors, such as side effects, dosing issues, efficacy and generic antipsychotic use, were associated with increased 
Table 1 Manuscripts that defined relapse and also discussed hospitalization used a range of definitions

\begin{tabular}{lll}
\hline $\begin{array}{l}\text { Way in which hospitalization is used } \\
\text { in references that also define relapse }\end{array}$ & $\begin{array}{l}\text { Number of times } \\
\text { hospitalization } \\
\text { defined (n) }\end{array}$ & References \\
\hline $\begin{array}{ll}\text { Hospitalization is discussed, separately } \\
\text { to relapse }\end{array}$ & $\begin{array}{l}\text { Bechdolf et al. [16]; Crown et al. [59]; dos Reis et al. [47]; Dyck et al. [32]; Hayhurst et al. } \\
\text { [33]; Miettunen et al. [40]; Olivares et al. [56]; Svarstad et al. [31]; Sun et al. [45]; }\end{array}$ \\
& $\begin{array}{l}\text { Rabinowitz et al. [30]; Taylor et al. [22]; Thompson et al. [36]; Usall et al. [37]; Ward et al. } \\
\text { [25]; Weiden et al. [26]; Whitehorn et al. [39]; Janicak et al. [48]; Zhu et al. [50]; Bechdolf }\end{array}$ \\
& $\begin{array}{l}\text { et al. [15]; Drake et al. [20]; Novák-Grubic and Tacvar [34]; Olivares et al. [23]; Valencia } \\
\text { et al. [46]; Kim [54]; Peuskens et al. [24] }\end{array}$
\end{tabular}

Hospitalization equates to relapse $10 \quad$ Buckley et al. [44]; de Sena et al. [35]; Hawley et al. [58]; Leucht et al. [30]; Malik et al. [1 1]; Rouillon et al. [49]; Spaniel et al. [52]; Spaniel et al. [53]; Taylor et al. [22]; Turkington et al. [42]

Hospitalization used as a component $\quad 14$ of relapse definition

Almond et al. [38]; Ascher-Svanum et al. [57]; Csernansky et al. [17]; Drake et al. [20]; Emsley et al. [18]; Gaertner et al. [28]; Gasquet et al. [55]; Haro et al. [21]; Haro et al. [51]; Hickling et al. [29]; Hong et al. [19]; Muirhead et al. [41]; Pharoah et al. [27]; Xiang et al. [43]

Exacerbation of symptoms leading 7 Berglund et al. [95]; Chabannes et al. [96]; Drake et al. [20]; Lancon et al. [93]; Simpson to hospitalization equates to relapse et al. [66]; Tomaras et al. [92]; Wahlbeck et al. [94]

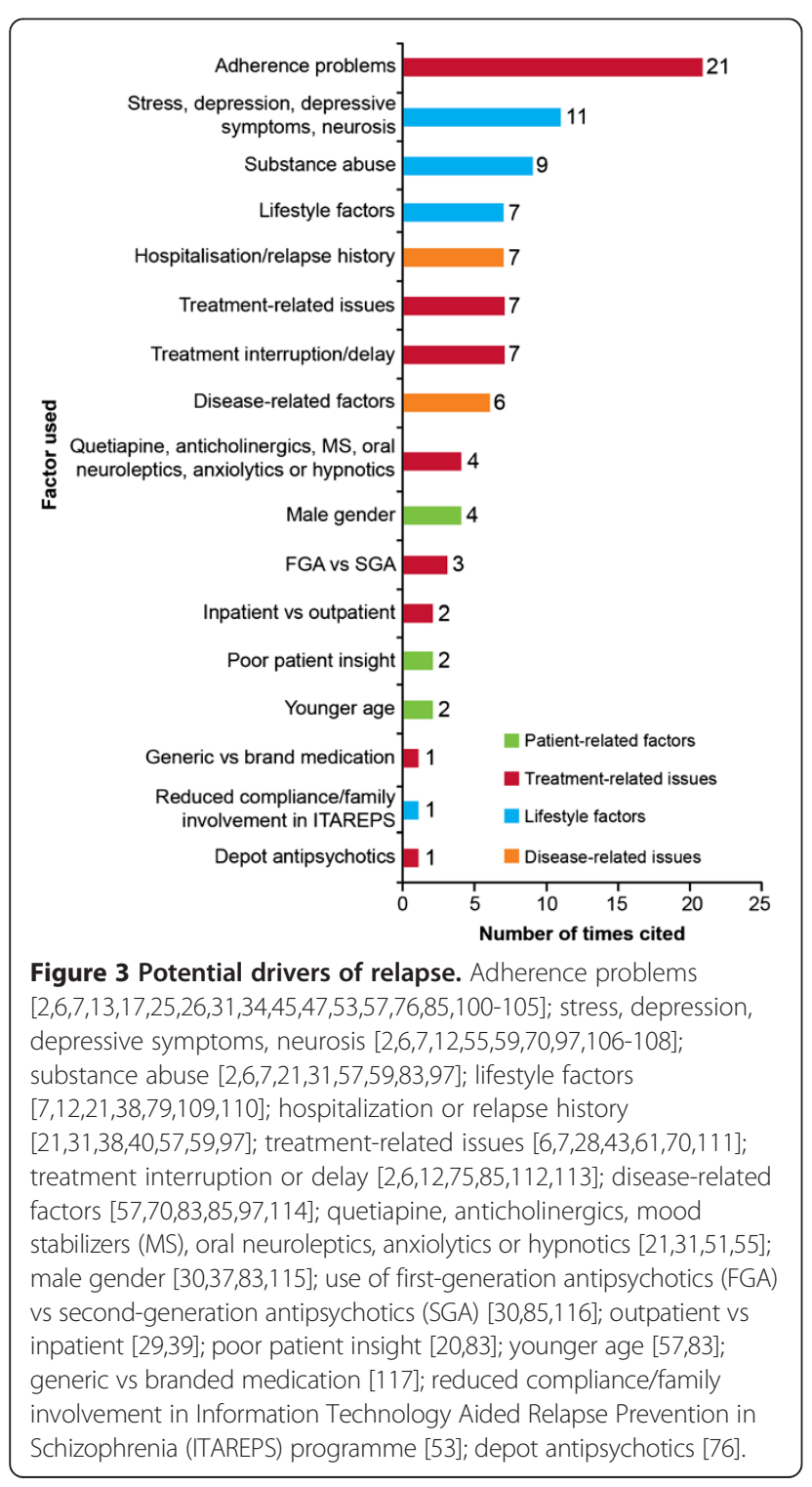

relapse rates (Figure 3). Delay in treatment delivery and interruptions to treatment due to loss of medical insurance coverage were also identified. In one study, a longer duration of untreated psychosis was significantly associated with mild relapse in the first year after hospitalization (Kruskal-Wallis test $\chi^{2}=5.31, p=0.02$ ). In this study, a mild relapse was defined as a recurrence or exacerbation of psychotic symptoms in 1 week for which an increase in antipsychotic medication was required, without a significant decline in social functioning [75]. A regression model analysis in another study indicated that patients who were subject to interruptions in Medicaid coverage were more likely to be hospitalized (negative binomial regression $z=6.9, p<0.001$ ), experience a greater number of hospitalizations (negative binomial regression $z=8.4, p<0.001$ ) and spend $61 \%$ more days in the hospital compared with patients with continuous coverage (exponential regression model $z=7.1$, $p<0.001)[112]$.

\section{Factors that may reduce the rate of relapse}

There were 49 occurrences (in 46 publications) of factors that may reduce the rate of relapse (Figure 4). The potential for antipsychotic therapy to reduce relapse rates was examined in a total of 25 publications. One publication reported the results from a 3-year follow-up of a large cohort of outpatients with schizophrenia taking part in the prospective, observational European Schizophrenia Outpatient Health Outcomes (SOHO) study $(n=6516)$ [21]. In this study, relapse rates were higher in patients who took typical antipsychotics (depot (relative risk $(\mathrm{RR})=1.689 ; 95 \% \mathrm{CI}=1.306,2.184$; $p<0.0001)$ or oral $(\mathrm{RR}=1.655 ; 95 \% \mathrm{CI}=1.316,2.081$; $p<0.0001)$ ) than the atypical antipsychotic olanzapine. Differences in the RR for relapse were also observed between olanzapine and other second-generation antipsychotics (SGAs) [21]. 


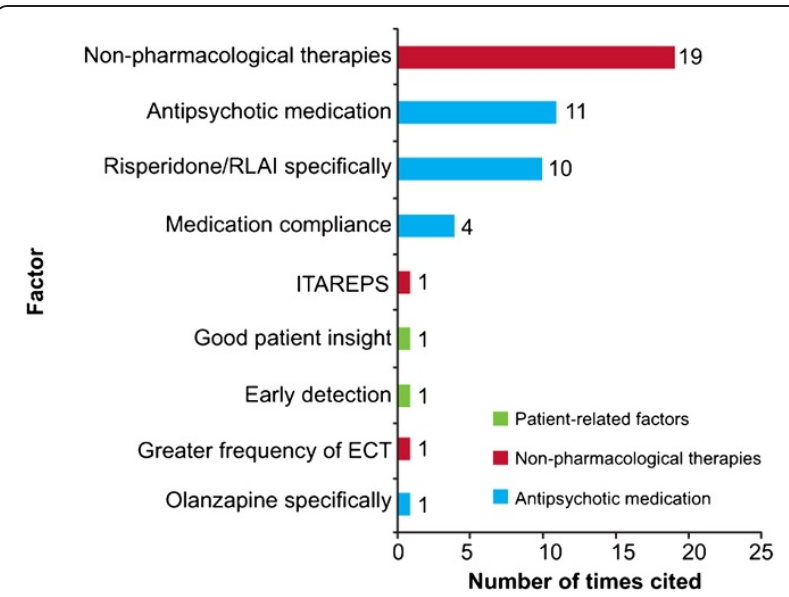

Figure 4 Factors that may reduce relapse rates. Individual citations of each factor: a single reference may include citations of more than one factor. The antipsychotic medication category does not include the other pharmacological therapy factors. Nonpharmacological therapies $[4-6,11,14-16,27,32,41,42,64,82,84,92,118-121]$ antipsychotic medication $[4,6,23,54,81,122-127]$; risperidone/risperidone long-acting injectable (RLAl) specifically [22-24,35,65,74,128-131]; medication compliance [25,33,132,133]; Information Technology Aided Relapse Prevention in Schizophrenia (ITAREPS) [52]; good patient insight [134]; early detection [135]; greater frequency of electroconvulsive therapy (ECT) [90]; olanzapine specifically [21].

Another study showed that patients who were treated with depot antipsychotics had a higher rate of major relapses and hospitalization compared with patients who had not received depot antipsychotics [76]. However, this study primarily examined the outcome of therapy in relation to medication adherence and defined a 'depot patient' as one who had received a depot antipsychotic 'at any time during the study', which included patients who started therapy with an oral antipsychotic but were later switched to a depot antipsychotic due to poor adherence. Therefore, the extent to which adherence problems caused both the switch to depot antipsychotic therapy and the relapse in these 'depot patients' is unclear. Moreover, it was not reported whether relapse occurred prior to, or following, initiation of treatment with the depot antipsychotic [76].

The effect of risperidone long-acting injectable (RLAI) on relapse rates and duration of hospitalization or relapse compared with baseline $[22,128]$ or compared with patients treated with oral antipsychotics was reported in several publications $[18,23]$. In one post hoc analysis of two similarly designed 2-year studies (one RLAI and one oral antipsychotic study), RLAI administration was associated with a relapse rate of $9.3 \%$ compared with $42.1 \%$ in patients treated with oral antipsychotics $(p=0.001)$ [18]. In a study comparing hospitalization at 1 and 2 years after RLAI initiation, greater decreases from baseline in the number of patients hospitalized and the number and length of hospital stays in patients who continued with RLAI treatment were observed, compared with those who discontinued [24].

Non-pharmacological interventions, such as psychoeducation and cognitive behavioural therapy (CBT), were also commonly reported as factors that may reduce relapse. However, these interventions were evaluated in patients already receiving treatment with antipsychotic medication [4]. Many publications highlighted a 'trend' associating therapies such as CBT and psychoeducation with relapse reduction but failed to demonstrate statistically significant effects in observational or naturalistic settings.

\section{Discussion}

The consistent and correct assessment and management of relapse in patients with schizophrenia are vital for clinical practice and important factors for controlled clinical trials. As such, an awareness of the factors that may be associated with increased and decreased rates of relapse should invariably aid clinical practice and benefit patients. However, reporting physicians do not always state how they define relapse; only $62 \%(87 / 145)$ of the final selection of journal articles identified in this literature search stated a definition of relapse. Interestingly, none of the international and national guidelines define relapse, potentially indicating that in clinical practice, a psychiatrist is deemed able to identify a relapsing patient. Alternatively, acutely exacerbated patients may present with a range of signs and symptoms to such a variable degree as to hinder the provision of a unique reliable definition of relapse.

Csernansky and colleagues [17] proposed a set of multifactorial criteria for defining relapse, including hospitalization, and suggested that any single factor could be used as a clinical determinant of relapse. Within the studies identified in this search, many factors were used to define relapse. Hospitalization, usually defined in generic terms of 'hospitalization' or 'psychiatric hospitalization', was the single factor most commonly used to define relapse and represents a commonly used proxy for examining relapse; however, hospitalization was also one of the search terms used and so may bias the results. In particular, the majority of the retrospective database analyses identified in this literature search specifically investigated hospitalization when conducting their analyses, rather than relapse or other parameters that could potentially be used to define relapse (that may not have been available in the original data source). It is also likely that hospitalization is frequently used to define relapse since it is simple to measure and provides tangible data to analyse. However, schizophrenia is a heterogeneous condition in which a patient might relapse (moderate symptom exacerbation) and not be hospitalized or conversely might be hospitalized for other reasons, such as 
social or somatic causes, but have relatively stable psychiatric symptoms.

Clinical scales and criteria were also frequently identified in the literature and provide a clinically validated and standardized method of assessment. In clinical studies, where symptoms are measured at baseline and then at set intervals, scales are ideal to characterize patients; however, they can be time-consuming and require additional training to perform since most of them are not intuitive, and are therefore often inconvenient for use in routine clinical practice. Behavioural changes and clinical assessments were least frequently used to define relapse in patients with schizophrenia and were poorly defined in the literature, but are likely to be used in everyday clinical practice. The low frequency of use in clinical studies probably reflects that physician variability may be a significant factor in behavioural and clinical definitions.

Factors that were associated with an increased or decreased risk of relapse included adherence to medication, stress, psychosocial therapies, previous hospitalization/relapse and patient insight. The most prominent factor related to increased risk of relapse was partial/non-adherence to antipsychotic medication $[25,76,85]$. Indeed, it is well established that treatment with antipsychotic medication can offer an effective option for relapse prevention as well as other beneficial patient outcomes. For instance, in an analysis of a nationwide cohort of 2,588 consecutive patients hospitalized for the first time with a diagnosis of schizophrenia in Finland, 1,496 patients (57.8\%) were rehospitalized due to relapse during a mean follow-up period of 2 years; use of any antipsychotic was associated with a lower risk of rehospitalization compared with no use of antipsychotics (Cox model hazard ratio $=0.38$, 95\% CI $=0.34-0.43$; marginal structural model hazard ratio $=0.48,95 \% \mathrm{CI}=0.42-0.56)[136]$.

Increasing gaps in medication intake over 1 year can result in a greater risk of hospitalization (up to a fourfold increase) [26]. The use of continuous medication, through increased adherence to antipsychotic medication or use of medications that give assured delivery, was the most frequently identified factor associated with reduced relapse or hospitalization rates $[18,22,23,128]$. These findings highlight the current focus on antipsychotic medication in the literature and the importance of monitoring and improving medication adherence in patients with schizophrenia.

While primary research articles concerning RCTs were removed from the initial results for the reasons outlined above (see 'Methods'), the literature search identified one meta-analysis performed by Leucht et al. [86], covering $17 \mathrm{RCTs}$, where the heterogeneity of definitions of relapse used mirrored those seen in naturalistic studies. With the exception of RCTs conducted by the same pharmaceutical company, each study used a distinct definition of relapse. Nevertheless, hospitalization, due to an exacerbation of psychotic symptoms, was a key component of most of the methods used to define relapse. While the search was designed to capture definitions of relapse as they relate to routine clinical practice, rather than more selected clinical populations, nevertheless consideration of RCTs of antipsychotic treatments is informative, particularly in terms of their impact on relapse reduction since this is frequently included as one of the study outcomes. Systematic review and meta-analysis of RCTs are often used as a method of comparing the effects of different antipsychotics. One such study suggested that SGAs may have a greater ability to prevent relapse than first-generation antipsychotics (FGAs) [86], but the influence of patient adherence to treatment on this finding is uncertain, and the extent of the difference varied between treatments [137].

A number of meta-analyses have been conducted of relapse rates of depot/long-acting injectable (LAI) antipsychotics compared with oral antipsychotics based on RCTs; however, the study conclusions are not all in agreement. Leucht et al. [138] reported that in studies of 12 months or more comparing depot with oral antipsychotics in schizophrenia, depot formulations reduced relapse significantly, with a relative and absolute risk of $30 \%$ and $10 \%$, respectively $(\mathrm{RR}=0.70 ; 95 \% \mathrm{CI}=0.57$, 0.87 ; number needed to treat $(\mathrm{NNT})=10 ; 95 \% \mathrm{CI}=6$, $25 ; p=0.0009)$. A similar superiority of depot over oral formulations $(\mathrm{RR}=0.31 ; 95 \% \mathrm{CI}=0.21-0.41$ vs $\mathrm{RR}=$ $0.46 ; 95 \% \mathrm{CI}=0.37-0.57 ; p=0.03$ ) has been reported in a meta-analysis of RCTs of antipsychotics versus placebo for relapse prevention in schizophrenia [139]. However, a meta-analysis published subsequently by some of the same authors found no superiority of pooled LAIs compared with oral antipsychotics in relapse prevention (studies $=21, n=4950, \mathrm{RR}=0.93 ; 95 \% \mathrm{CI}=0.80,1.08$; $p=0.35)$ [140]. The authors speculated that publication bias in older studies (prior to requirements for registration and publication of results of all clinical trials), changing definitions of relapse over time and increasing use of oral SGAs as comparators may all influence the difference in findings between older and more recent RCTs. One interpretation of these differences in findings is that RCTs may over-represent patients with greater adherence to treatment, and with less severe illness compared with the wider population of patients with schizophrenia. Consistent with this assertion, a meta-analysis of mirror-image open studies (pre- and post-introduction of LAI antipsychotics) within subjects showed a strong superiority of LAI antipsychotics in preventing a next hospitalization (16 studies, $n=4,066$; $\mathrm{RR}=0.43 ; 95 \% \mathrm{CI}=$ $0.35-0.53 ; p<0.001$, NNT $=3$ ) and in decreasing the number of hospitalizations (15 studies, 6,396 person- 
years, rate ratio $=0.38 ; 95 \% \mathrm{CI}=0.28,0.51 ; p<0.001)$ [141]. This clear superiority was maintained in subgroup analyses of FGA LAI antipsychotics, SGA LAI antipsychotics, studies published before 2000, studies published after 2000, studies reporting intention-to-treat analyses and studies reporting observed cases, with the authors concluding that analyses of naturalistic studies may better represent the clinical population likely to be treated with LAI antipsychotics in routine care.

In non-RCTs identified in the current literature review, non-pharmacological interventions, such as psychoeducation and CBT, were also commonly reported as factors that may reduce relapse and were recommended as important components of schizophrenia management strategies by national guidelines [4].

\section{Conclusions}

In conclusion, this literature search identified numerous factors that have been used to define relapse. Hospitalization was the factor most frequently used to define relapse, and this represents a useful proxy for relapse when reporting in a naturalistic setting. Several factors are reported potentially to increase or decrease the risk of relapse in patients with schizophrenia. Although reliable predictors for relapse have not been identified, observation of these factors may aid the identification of at-risk patients. Continuous antipsychotic medication appears to be one of the most prominently reported factors to reduce the risk of relapse and should be a priority for psychiatrists.

\section{Competing interests}

José M Olivares has participated in regional, national and international advisory boards for Janssen-Cilag, Lilly, Astra-Zeneca and Bristol-Myers Squibb; has been involved in the design and conduct of clinical trials for Janssen-Cilag, Lilly, Astra-Zeneca, Pfizer, Lundbeck, GlaxoSmithKline and Bristol-Myers Squibb; and has received educational grants for research, honoraria and travel support for activities as a consultant/ adviser and lecturer/faculty member for Janssen-Cilag, Lilly, Astra-Zeneca, Pfizer, Lundbeck, GlaxoSmithKline, Novartis and Bristol-Myers Squibb. Andreas Schreiner is a shareholder of Johnson \& Johnson. Jan Sermon is a full-time employee of Janssen-Cilag NV/SA. Michiel Hemels is a full-time employee of Janssen Health Economics Market Access and Reimbursement, Europe, Middle East and Africa. Andreas Schreiner is a full-time employee of Janssen-Cilag Medical and Scientific Affairs Europe, Middle East and Africa.

\section{Authors' contributions}

JMO, JS, MH and AS contributed to the development and content of the manuscript and to the interpretation of the search findings and provided guidance on both. All authors read and approved the final manuscript and were responsible for taking the decision to submit the paper for publication.

\section{Acknowledgements}

Ann Smet, Angelika Mehnert and Lupe Martinez contributed to the review of the search findings and the early development of the manuscript. ApotheCom ScopeMedical Ltd., Sevenoaks, UK, provided medical writing and editorial assistance in the preparation of the manuscript, on behalf of Janssen. This included developing the manuscript in line with the authors' interpretation of the search results and also performing the literature search.

\section{Author details}

'Department of Psychiatry, Hospital Meixoeiro, Complejo Hospitalario Universitario de Vigo, Vigo 36200, Spain. ${ }^{2}$ Janssen-Cilag NV/SA, Antwerpseweg 15-17, Beerse 2340, Belgium. ${ }^{3}$ Janssen Health Economics Market Access and Reimbursement, Europe, Middle East and Africa, Hammerbakken 19, Birkerød 3460, Denmark. ${ }^{4}$ Medical and Scientific Affairs, Janssen-Cilag Europe, Middle East and Africa, Johnson \& Johnson Platz 5a, Neuss 41470, Germany.

Received: 20 November 2012 Accepted: 7 October 2013

Published: 23 October 2013

\section{References}

1. Jablensky A, Sartorius N, Ernberg G, Anker M, Korten A, Cooper JE, Day R, Bertelsen A: Schizophrenia: manifestations, incidence and course in different cultures. A World Health Organization ten-country study. Psychol Med Monogr Suppl 1992, 20:1-97.

2. Falkai P, Wobrock T, Lieberman J, Glenthoj B, Gattaz WF, Moller HJ: World Federation of Societies of Biological Psychiatry (WFSBP) guidelines for biological treatment of schizophrenia, part 1: acute treatment of schizophrenia. World J Biol Psychiatry 2005, 6:132-191.

3. Andreasen NC, Carpenter WT Jr, Kane JM, Lasser RA, Marder SR, Weinberger DR: Remission in schizophrenia: proposed criteria and rationale for consensus. Am J Psychiatry 2005, 162:441-449.

4. National Institute for Clinical Excellence: Schizophrenia: Core Interventions in the Treatment and Management of Schizophrenia in Primary and Secondary Care (Update). National Clinical Practice Guidelines Number 82. London: NICE; 2009:210.

5. Falkai P, Wobrock T, Lieberman J, Glenthoj B, Gattaz WF, Moller HJ: World Federation of Societies of Biological Psychiatry (WFSBP) guidelines for biological treatment of schizophrenia, part 2: long-term treatment of schizophrenia. World J Biol Psychiatry 2006, 7:5-40.

6. Lehman AF, Lieberman JA, Dixon LB, McGlashan TH, Miller AL, Perkins DO, Kreyenbuhl J: Practice guideline for the treatment of patients with schizophrenia, second edition. Am J Psychiatry 2004, 161(Suppl 2):1-56.

7. Taylor M, Chaudhry I, Cross M, McDonald E, Miller P, Pilowsky L, Strickland P: Towards consensus in the long-term management of relapse prevention in schizophrenia. Hum Psychopharmacol 2005, 20:175-181.

8. Kane JM: Treatment strategies to prevent relapse and encourage remission. J Clin Psychiatry 2007, 68(Suppl 14):27-30.

9. Kane JM: Treatment adherence and long-term outcomes. CNS Spectr 2007, 12:21-26.

10. Awad AG, Voruganti LN: The burden of schizophrenia on caregivers: a review. Pharmacoeconomics 2008, 26:149-162.

11. Malik N, Kingdon D, Pelton J, Mehta R, Turkington D: Effectiveness of brief cognitive-behavioral therapy for schizophrenia delivered by mental health nurses: relapse and recovery at 24 months. J Clin Psychiatry 2009, 70:201-207.

12. Muller N: Mechanisms of relapse prevention in schizophrenia. Pharmacopsychiatry 2004, 37(Suppl 2):S141-S147.

13. Samalin L, Blanc O, Llorca PM: Optimizing treatment of schizophrenia to minimize relapse. Expert Rev Neurother 2010, 10:147-150.

14. Dixon LB, Perkins DO, Calmes C: Guideline Watch (September 2009): Practice Guideline for the Treatment of Patients with Schizophrenia. APA Practice Guidelines. Arlington: APA; 2009:1-10.

15. Bechdolf A, Knost B, Kuntermann C, Schiller S, Klosterkotter J, Hambrecht M, Pukrop R: A randomized comparison of group cognitive-behavioural therapy and group psychoeducation in patients with schizophrenia. Acta Psychiatr Scand 2004, 110:21-28.

16. Bechdolf A, Kohn D, Knost B, Pukrop R, Klosterkotter J: A randomized comparison of group cognitive-behavioural therapy and group psychoeducation in acute patients with schizophrenia: outcome at 24 months. Acta Psychiatr Scand 2005, 112:173-179.

17. Csernansky JG, Mahmoud R, Brenner R: A comparison of risperidone and haloperidol for the prevention of relapse in patients with schizophrenia. N Engl J Med 2002, 346:16-22.

18. Emsley R, Oosthuizen P, Koen L, Niehaus DJ, Medori R, Rabinowitz J: Oral versus injectable antipsychotic treatment in early psychosis: post hoc comparison of two studies. Clin Ther 2008, 30:2378-2386.

19. Hong J, Windmeijer F, Novick D, Haro JM, Brown J: The cost of relapse in patients with schizophrenia in the European SOHO (Schizophrenia 
Outpatient Health Outcomes) study. Prog Neuropsychopharmacol Biol Psychiatry 2009, 33:835-841.

20. Drake RJ, Dunn G, Tarrier N, Bentall RP, Haddock G, Lewis SW: Insight as a predictor of the outcome of first-episode nonaffective psychosis in a prospective cohort study in England. J Clin Psychiatry 2007, 68:81-86.

21. Haro JM, Novick D, Suárez D, Alonso J, Lépine JP, Ratcliffe M: Remission and relapse in the outpatient care of schizophrenia: three-year results from the Schizophrenia Outpatient Health Outcomes study. J Clin Psychopharmacol 2006, 26:571-578.

22. Taylor M, Currie A, Lloyd K, Price M, Peperell K: Impact of risperidone long acting injection on resource utilization in psychiatric secondary care. J Psychopharmacol 2008, 22:128-131.

23. Olivares JM, Rodriguez-Morales A, Diels J, Povey M, Jacobs A, Zhao Z, Lam A, Vega JC, Cuellar JA, de Castro FJ, Quintero CM, Martiin JF, Domínguez P, Ojeda JL, Cortés SS, Cala FI, Marín CG, Castro LM, Duaso MA, Albarracín JR, Vergara GN, Benítez AF, Cleries FM, Pérez-Brian JM, Aragón AB, Navarro JC, Biedma JA, de Pedro RB, González JF, López ME, et al: Long-term outcomes in patients with schizophrenia treated with risperidone long-acting injection or oral antipsychotics in Spain: results from the electronic Schizophrenia Treatment Adherence Registry (e-STAR). Eur Psychiatry 2009, 24:287-296.

24. Peuskens J, Olivares JM, Pecenak J, Tuma I, Bij de Weg H, Eriksson L, Resseler $\mathrm{S}$, Akhras $\mathrm{K}$, Jacobs A: Treatment retention with risperidone long-acting injection: 24-month results from the Electronic Schiophrenia Treatment Adherence Registry (e-STAR) in six countries. Curr Med Res Opin 2010, 26:501-509.

25. Ward A, Ishak K, Proskorovsky I, Caro J: Compliance with refilling prescriptions for atypical antipsychotic agents and its association with the risks for hospitalization, suicide, and death in patients with schizophrenia in Quebec and Saskatchewan: a retrospective database study. Clin Ther 2006, 28:1912-1921.

26. Weiden PJ, Kozma C, Grogg A, Locklear J: Partial compliance and risk of rehospitalization among California Medicaid patients with schizophrenia. Psychiatr Serv 2004, 55:886-891.

27. Pharoah FM, Mari JJ, Streiner D: Family intervention for schizophrenia. Cochrane Database Syst Rev 2000, 2:CD000088

28. Gaertner I, Gaertner HJ, Vonthein R, Dietz K: Therapeutic drug monitoring of clozapine in relapse prevention: a five-year prospective study. J Clin Psychopharmacol 2001, 21:305-310.

29. Hickling FW, McCallum M, Nooks L, Rodgers-Johnson P: Outcome of first contact schizophrenia in Jamaica. West Indian Med J 2001, 50:194-197.

30. Rabinowitz J, Lichtenberg P, Kaplan Z, Mark M, Nahon D, Davidson M: Rehospitalization rates of chronically ill schizophrenic patients discharged on a regimen of risperidone, olanzapine, or conventional antipsychotics. Am J Psychiatry 2001, 158:266-269.

31. Svarstad BL, Shireman TI, Sweeney JK: Using drug claims data to assess the relationship of medication adherence with hospitalization and costs. Psychiatr Serv 2001, 52:805-811.

32. Dyck DG, Hendryx MS, Short RA, Voss WD, McFarlane WR: Service use among patients with schizophrenia in psychoeducational multiple-family group treatment. Psychiatr Serv 2002, 53:749-754.

33. Hayhurst KP, Brown P, Lewis SW: The cost-effectiveness of clozapine: a controlled, population-based, mirror-image study. J Psychopharmacol 2002, 16:169-175.

34. Novák-Grubic $V$, Tavcar R: Predictors of noncompliance in males with first-episode schizophrenia, schizophreniform and schizoaffective disorder. Eur Psychiatry 2002, 17:148-154.

35. de Sena EP, Santos-Jesus R, Miranda-Scippa A, Quarantini Lde C, Oliveira IR: Relapse in patients with schizophrenia: a comparison between risperidone and haloperidol. Rev Bras Psiquiatr 2003, 25:220-223.

36. Thompson EE, Neighbors HW, Munday C, Trierweiler S: Length of stay, referral to aftercare, and rehospitalization among psychiatric inpatients. Psychiatr Serv 2003, 54:1271-1276.

37. Usall J, Ochoa S, Araya S, Marquez M: Gender differences and outcome in schizophrenia: a 2-year follow-up study in a large community sample. Eur Psychiatry 2003, 18:282-284

38. Almond S, Knapp M, Francois C, Toumi M, Brugha T: Relapse in schizophrenia: costs, clinical outcomes and quality of life. Br J Psychiatry 2004, 184:346-351.

39. Whitehorn D, Richard JC, Kopala LC: Hospitalization in the first year of treatment for schizophrenia. Can J Psychiatry 2004, 49:635-638
40. Miettunen J, Lauronen E, Veijola J, Koponen H, Saarento O, Isohanni M: Patterns of psychiatric hospitalizations in schizophrenic psychoses within the Northern Finland 1966 birth cohort. Nord J Psychiatry 2006, 60:286-293.

41. Muirhead D, Harvey C, Ingram G: Effectiveness of community treatment orders for treatment of schizophrenia with oral or depot antipsychotic medication: clinical outcomes. Aust N Z J Psychiatry 2006, 40:596-605

42. Turkington D, Kingdon D, Rathod S, Hammond K, Pelton J, Mehta R: Outcomes of an effectiveness trial of cognitive-behavioural intervention by mental health nurses in schizophrenia. Br J Psychiatry 2006, 189:36-40.

43. Xiang YQ, Zhang ZJ, Weng YZ, Zhai YM, Li WB, Cai ZJ, Tan QR, Wang CY: Serum concentrations of clozapine and norclozapine in the prediction of relapse of patients with schizophrenia. Schizophr Res 2006, 83:201-210.

44. Buckley LA, Pettit T, Adams CE: Supportive therapy for schizophrenia. Cochrane Database Syst Rev 2007, 3:CD004716.

45. Sun SX, Liu GG, Christensen DB, Fu AZ: Review and analysis of hospitalization costs associated with antipsychotic nonadherence in the treatment of schizophrenia in the United States. Curr Med Res Opin 2007, 23:2305-2312

46. Valencia M, Rascon ML, Juarez F, Murow E: A psychosocial skills training approach in Mexican out-patients with schizophrenia. Psychol Med 2007, 37:1393-1402.

47. DosReis S, Johnson E, Steinwachs D, Rohde C, Skinner EA, Fahey M, Lehman AF: Antipsychotic treatment patterns and hospitalizations among adults with schizophrenia. Schizophr Res 2008, 101:304-311.

48. Janicak PG, WU JH, Mao L: Hospitalization rates before and after initiation of paliperidone ER in patients with schizophrenia: results from openlabel extensions of the US double-blind trials. Curr Med Res Opin 2008, 24:1807-1815.

49. Rouillon F, Chartier F, Gasquet I: Strategies of treatment with olanzapine in schizophrenic patients during stable phase: results of a pilot study. Eur Neuropsychopharmacol 2008, 18:646-652.

50. Zhu B, Ascher-Svanum H, Faries DE, Peng X, Salkever D, Slade EP: Costs of treating patients with schizophrenia who have illness-related crisis events. BMC Psychiatry 2008, 8:72

51. Haro JM, Ciudad A, Alonso J, Bousoño M, Suárez D, Novick D, Gilaberte Remission and relapse in the outpatient treatment of patients with schizophrenia. Outcomes at 3 years. Actas Esp Psiquiatr 2008, 36:187-196.

52. Spaniel F, Vohlídka P, Kozený J, Novák T, Hrdlicka J, Motlová L, Cermák J, Höschl C: The Information Technology Aided Relapse Prevention Programme in Schizophrenia: an extension of a mirror-design follow-up. Int J Clin Pract 2008, 62:1943-1946.

53. Spaniel F, Vohlídka P, Hrdlicka J, Kozený J, Novák T, Motlová L, Cermák J, Bednarík J, Novák D, Höschl C: ITAREPS: information technology aided relapse prevention programme in schizophrenia. Schizophr Res 2008, 98:312-317.

54. Kim JH, Kim D, Marder SR: Time to rehospitalization of clozapine versus risperidone in the naturalistic treatment of comorbid alcohol use disorder and schizophrenia. Prog Neuropsychopharmacol Biol Psychiatry 2008, 32:984-988.

55. Gasquet I, Chartier F, Tcherny-Lessenot S, Lépine JP: The European Schizophrenia Outpatient Health Outcomes Study: observational study over 36 months of the French cohort of schizophrenic outpatients treated with antipsychotics. Rev Epidemiol Sante Publique 2009, 57:25-32.

56. Olivares JM, Peuskens J, Pecenak J, Resseler S, Jacobs A, Akhras KS: Clinical and resource-use outcomes of risperidone long-acting injection in recent and long-term diagnosed schizophrenia patients: results from a multinational electronic registry. Curr Med Res Opin 2009, 25:2197-2206.

57. Ascher-Svanum H, Zhu B, Faries DE, Salkever D, Slade EP, Peng X, Conley RR: The cost of relapse and the predictors of relapse in the treatment of schizophrenia. BMC Psychiatry 2010, 10:2.

58. Hawley C, Turner M, Latif MA, Curtis V, Saleem PT, Wilton K: Switching stable patients with schizophrenia from depot and oral antipsychotics to long-acting injectable risperidone: reasons for switching and safety. Hum Psychopharmacol 2010, 25:37-46.

59. Crown WH, Neslusan C, Russo PA, Holzer S, Ozminkowski R, Croghan T: Hospitalization and total medical costs for privately insured persons with schizophrenia. Adm Policy Ment Health 2001, 28:335-351.

60. Glick ID, Berg PH: Time to study discontinuation, relapse, and compliance with atypical or conventional antipsychotics in schizophrenia and related disorders. Int Clin Psychopharmacol 2002, 17:65-68. 
61. Lipkovich I, Deberdt W, Csernansky JG, Buckley P, Peuskens J, Kollack-Walker S, Zhang Y, Liu-Seifert H, Houston JP: Predictors of risk for relapse in patients with schizophrenia or schizoaffective disorder during olanzapine drug therapy. J Psychiatr Res 2007, 41:305-310.

62. Chrzanowski WK, Marcus RN, Torbeyns A, Nyilas M, McQuade RD: Effectiveness of long-term aripiprazole therapy in patients with acutely relapsing or chronic, stable schizophrenia: a 52-week, open-label comparison with olanzapine. Psychopharmacology (Berl) 2006 189:259-266.

63. Simonsen E, Friis S, Haahr U, Johannessen JO, Larsen TK, Melle I, Opjordsmoen S, Rund BR, Vaglum P, McGlashan T: Clinical epidemiologic first-episode psychosis: 1-year outcome and predictors. Acta Psychiatr scand 2007, 116:54-61.

64. Lee SH, Choi TK, Suh S, Kim YW, Kim B, Lee E, Yook KH: Effectiveness of a psychosocial intervention for relapse prevention in patients with schizophrenia receiving risperidone via long-acting injection. Psychiatry Res 2010, 175:195-199.

65. Emsley R, Medori R, Koen L, Oosthuizen PP, Niehaus DJ, Rabinowitz J: Long-acting injectable risperidone in the treatment of subjects with recent-onset psychosis: a preliminary study. J Clin Psychopharmacol 2008, 28:210-213.

66. Simpson GM, Mahmoud RA, Lasser RA, Kujawa M, Bossie CA, Turkoz I, Rodriguez S, Gharabawi GM: A 1-year double-blind study of 2 doses of long-acting risperidone in stable patients with schizophrenia or schizoaffective disorder. J Clin Psychiatry 2006, 67:1194-1203.

67. Bayle FJ, Misdrahi D, Llorca PM, Lancon C, Olivier V, Quintin P, Azorin JM: Acute schizophrenia concept and definition: investigation of a French psychiatrist population. Encéphale 2005, 31:10-17.

68. Gleeson JF, Rawlings D, Jackson HJ, McGorry PD: Early warning signs of relapse following a first episode of psychosis. Schizophr Res 2005, 80:107-111.

69. Kho KH, Blansjaar BA, de Vries, Babuskova D, Zwinderman AH, Linszen DH: Electroconvulsive therapy for the treatment of clozapine nonresponders suffering from schizophrenia-an open label study. Eur Arch Psychiatry Clin Neurosci 2004, 254:372-379.

70. Chabungbam G, Avasthi A, Sharan P: Sociodemographic and clinical factors associated with relapse in schizophrenia. Psychiatry Clin Neurosci 2007, 61:587-593.

71. Knapp M, Locklear J, Jarbrink K: Impact of psychotic relapse definitions in assessing drug efficacy and costs: comparison of quetiapine XR, olanzapine and paliperidone ER. Curr Med Res Opin 2009, 25:1593-1603.

72. Kim B, Lee SH, Choi TK, Suh S, Kim YW, Lee E, Yook KH: Effectiveness of risperidone long-acting injection in first-episode schizophrenia: in naturalistic setting. Prog Neuropsychopharmacol Biol Psychiatry 2008, 32:1231-1235.

73. Dossenbach M, Arango-Dávila C, Silva IH, Landa E, Aguilar J, Caro O, Leadbetter J, Assunção S: Response and relapse in patients with schizophrenia treated with olanzapine, risperidone, quetiapine, or haloperidol: 12-month follow-up of the Intercontinental Schizophrenia Outpatient Health Outcomes (IC-SOHO) study. J Clin Psychiatry 2005, 66:1021-1030

74. Olivares JM, Rodriguez-Martinez A, Burón JA, Onso-Escolano D, RodriguezMorales A: Cost-effectiveness analysis of switching antipsychotic medication to long-acting injectable risperidone in patients with schizophrenia: a 12- and 24-month follow-up from the e-STAR database in Spain. Appl Health Econ Health Policy 2008, 6:41-53.

75. de Haan L, Linszen DH, Lenior ME, de Win ED, Gorsira R: Duration of untreated psychosis and outcome of schizophrenia: delay in intensive psychosocial treatment versus delay in treatment with antipsychotic medication. Schizophr Bull 2003, 29:341-348

76. Morken G, Widen JH, Grawe RW: Non-adherence to antipsychotic medication, relapse and rehospitalisation in recent-onset schizophrenia BMC Psychiatry 2008, 8:32.

77. Burns T, Fiander M, Audini B: A delphi approach to characterising "relapse" as used in UK clinical practice. Int J Soc Psychiatry 2000, 46:220-230.

78. Bai YM, Ting CT, Chen JY, Chang WH, Wu B, Hung CH, Kuo LW: Equivalent switching dose from oral risperidone to risperidone long-acting injection: a 48-week randomized, prospective, single-blind pharmacokinetic study. J Clin Psychiatry 2007, 68:1218-1225.

79. Mottaghipour Y, Pourmand D, Maleki H, Davidian L: Expressed emotion and the course of schizophrenia in Iran. Soc Psychiatry Psychiatr Epidemiol 2001, 36:195-199.
80. Bradley GM, Couchman GM, Perlesz A, Nguyen AT, Singh B, Riess C: Multiple-family group treatment for English- and Vietnamese-speaking families living with schizophrenia. Psychiatr Serv 2006, 57:521-530.

81. Morabia A, Ten Have T, Huguelet P, Ferrero F: Assessing efficacy of chronic therapy when disease is characterized by frequent relapses: the example of schizophrenia. J Clin Epidemiol 2002, 55:350-357.

82. Pharoah F, Mari J, Rathbone J, Wong W: Family intervention for schizophrenia. Cochrane Database Syst Rev 2006, 4:CD000088.

83. Csernansky JG, Schuchart EK: Relapse and rehospitalisation rates in patients with schizophrenia: effects of second generation antipsychotics. CNS Drugs 2002, 16:473-484.

84. Pharoah FM, Rathbone J, Mari JJ, Streiner D: Family intervention for schizophrenia. Cochrane Database Syst Rev 2003, 4:CD000088.

85. Uçok A, Polat A, Cakir S, Genç A: One year outcome in first episode schizophrenia. Predictors of relapse. Eur Arch Psychiatry Clin Neurosci 2006, 256:37-43.

86. Leucht S, Barnes TR, Kissling W, Engel RR, Correll C, Kane JM: Relapse prevention in schizophrenia with new-generation antipsychotics: a systematic review and exploratory meta-analysis of randomized, controlled trials. Am J Psychiatry 2003, 160:1209-1222.

87. Nuechterlein KH, Miklowitz DJ, Ventura J, Gitlin MJ, Stoddard M, Lukoff D: Classifying episodes in schizophrenia and bipolar disorder: criteria for relapse and remission applied to recent-onset samples. Psychiatry Res 2006, 144:153-166.

88. Linszen $D$, Dingemans $P$, Lenior M: Early intervention and a five year follow up in young adults with a short duration of untreated psychosis: ethical implications. Schizophr Res 2001, 51:55-61.

89. Suzuki K, Awata S, Matsuoka H: One-year outcome after response to ECT in middle-aged and elderly patients with intractable catatonic schizophrenia. J ECT 2004, 20:99-106.

90. Suzuki K, Awata S, Takano T, Ebina Y, Shindo T, Harada N, Matsuoka H: Adjusting the frequency of continuation and maintenance electroconvulsive therapy to prevent relapse of catatonic schizophrenia in middle-aged and elderly patients who are relapse-prone. Psychiatry Clin Neurosci 2006, 60:486-492.

91. Suzuki K, Awata S, Takano T, Ebina Y, Iwasaki H, Matsuoka H: Continuation electroconvulsive therapy for relapse prevention in middle-aged and elderly patients with intractable catatonic schizophrenia. Psychiatry Clin Neurosci 2005, 59:481-489.

92. Tomaras V, Mavreas V, Economou M, loannovich E, Karydi V, Stefanis C: The effect of family intervention on chronic schizophrenics under individual psychosocial treatment: a 3-year study. Soc Psychiatry Psychiatr Epidemiol 2000, 35:487-493.

93. Lançon C, Auquier P, Nayt G, Reine G: Stability of the five-factor structure of the Positive and Negative Syndrome Scale (PANSS). Schizophr Res 2000, 42:231-239.

94. Wahlbeck K, Cheine M, Essali MA: Clozapine versus typical neuroleptic medication for schizophrenia. Cochrane Database Syst Rev 2000, 2:CD000059.

95. Berglund N, Vahlne JO, Edman A: Family intervention in schizophreniaimpact on family burden and attitude. Soc Psychiatry Psychiatr Epidemiol 2003, 38:116-121.

96. Chabannes JP, Bazin N, Leguay D, Nuss P, Peretti CS, Tatu P, Hameg A, Garay RP, Ferreri M: Two-year study of relapse prevention by a new education program in schizophrenic patients treated with the same antipsychotic drug. Eur Psychiatry 2008, 23:8-13.

97. Moeller KE, Shireman TI, Liskow Bl: Relapse rates in patients with schizophrenia receiving aripiprazole in comparison with other atypical antipsychotics. J Clin Psychiatry 2006, 67:1942-1947.

98. Seuchter SA, Eisenacher M, Riesbeck M, Gaebel W, Köpcke W: Methods for predictor analysis of repeated measurements: application to psychiatric data. Methods Inf Med 2004, 43:184-191.

99. Montero I, Asencio A, Hernández I, Masanet MJ, Lacruz M, Bellver F, Iborra M, Ruiz I: Two strategies for family intervention in schizophrenia: a randomized trial in a Mediterranean environment. Schizophr Bull 2001, 27:661-670.

100. Law MR, Soumerai SB, Ross-Degnan D, Adams AS: A longitudinal study of medication nonadherence and hospitalization risk in schizophrenia. J Clin Psychiatry 2008, 69:47-53.

101. Misdrahi D, Llorca PM, Lancon C, Bayle FJ: Compliance in schizophrenia: predictive factors, therapeutical considerations and research implications. Encéphale 2002, 28:266-272. 
102. Masand PS, Narasimhan M: Improving adherence to antipsychotic pharmacotherapy. Curr Clin Pharmacol 2006, 1:47-56.

103. Hamann J, Cohen R, Leucht S, Busch R, Kissling W: Shared decision making and long-term outcome in schizophrenia treatment. J Clin Psychiatry 2007, 68:992-997.

104. Charpentier A, Goudemand M, Thomas P: Therapeutic alliance, a stake in schizophrenia. Encéphale 2009, 35:80-89.

105. Passerieux C, Caroli F, Giraud-Baro E: Persons suffering from schizophrenia and relapses. Encéphale 2009, 35:586-594.

106. Norman RM, Malla AK, McLean TS, McIntosh EM, Neufeld RW, Voruganti LP, Cortese L: An evaluation of a stress management program for individuals with schizophrenia. Schizophr Res 2002, 58:293-303.

107. Conley RR: The burden of depressive symptoms in people with schizophrenia. Psychiatr Clin North Am 2009, 32:853-861.

108. Bottai T, Cotton I, Drigeard A, Vaglio V: [Prodromes of schizophrenia recurrence. Encéphale 2009, 35(Suppl 1):S33-S40.

109. Kopelowicz A, Lopez SR, Zarate R, O'Brien M, Gordon J, Chang C, Gonzalez-Smith V: Expressed emotion and family interactions in Mexican Americans with schizophrenia. J Nerv Ment Dis 2006, 194:330-334.

110. Fortney JC, Xu S, Dong F: Community-level correlates of hospitalizations for persons with schizophrenia. Psychiatr Serv 2009, 60:772-778.

111. Faries DE, Ascher-Svanum $H$, Nyhuis AW, Kinon BJ: Clinical and economic ramifications of switching antipsychotics in the treatment of schizophrenia. BMC Psychiatry 2009, 9:54.

112. Harman JS, Manning WG, Lurie N, Christianson JB: Association between interruptions in Medicaid coverage and use of inpatient psychiatric services. Psychiatr Serv 2003, 54:999-1005.

113. Malla AK, Norman RM, Manchanda R, McLean TS, Harricharan R, Cortese L, Townsend LA, Scholten DJ: Status of patients with first-episode psychosis after one year of phase-specific community-oriented treatment. Psychiatr Serv 2002, 53:458-463.

114. Haro JM, Novick D, Suárez D, Ochoa S, Roca M: Predictors of the course of illness in outpatients with schizophrenia: a prospective three year study. Prog Neuropsychopharmacol Biol Psychiatry 2008, 32:1287-1292.

115. Grossman LS, Harrow M, Rosen C, Faull R: Sex differences in outcome and recovery for schizophrenia and other psychotic and nonpsychotic disorders. Psychiatr Serv 2006, 57:844-850

116. Essali A, Al-Haj HN, Li C, Rathbone J: Clozapine versus typical neuroleptic medication for schizophrenia. Cochrane Database Syst Rev 2009, 1:CD000059.

117. Kluznik JC, Walbek NH, Farnsworth MG, Melstrom K: Clinical effects of a randomized switch of patients from clozaril to generic clozapine. J Clin Psychiatry 2001, 62(Suppl 5):14-17.

118. Jones C, Cormac I, Mota J, Campbell C: Cognitive behaviour therapy for schizophrenia. Cochrane Database Syst Rev 2000, 2:CD000524.

119. Pitschel-Walz G, Leucht S, Bauml J, Kissling W, Engel RR: The effect of family interventions on relapse and rehospitalization in schizophrenia-a meta-analysis. Schizophr Bull 2001, 27:73-92.

120. Pekkala E, Merinder L: Psychoeducation for schizophrenia. Cochrane Database Syst Rev 2002, 2:CD002831.

121. Pfammatter M, Junghan UM, Brenner HD: Efficacy of psychological therapy in schizophrenia: conclusions from meta-analyses. Schizophr Bull 2006, 32(Suppl 1):S64-S80

122. Thornley B, Adams CE, Awad G: Chlorpromazine versus placebo for schizophrenia. Cochrane Database Syst Rev 2000, 2:CD000284.

123. Sultana A, McMonagle T: Pimozide for schizophrenia or related psychoses. Cochrane Database Syst Rev 2000, 3:CD001949.

124. Thornley B, Rathbone J, Adams CE, Awad G: Chlorpromazine versus placebo for schizophrenia. Cochrane Database Syst Rev 2003, 2:CD000284

125. El-Sayeh HG, Morganti C: Aripiprazole for schizophrenia. Cochrane Database Syst Rev 2006, 2:CD004578.

126. Rathbone J, McMonagle T: Pimozide for schizophrenia or related psychoses. Cochrane Database Syst Rev 2007, 3:CD001949.

127. Adams CE, Awad G, Rathbone J, Thornley B: Chlorpromazine versus placebo for schizophrenia. Cochrane Database Syst Rev 2007, 2:CD000284.

128. Leal A, Rosillon D, Mehnert A, Jarema M, Remington G: Healthcare resource utilization during 1-year treatment with long-acting, injectable risperidone. Pharmacoepidemiol Drug Saf 2004, 13:811-816.

129. Hunter RH, Joy CB, Kennedy E, Gilbody SM, Song F: Risperidone versus typical antipsychotic medication for schizophrenia. Cochrane Database Syst Rev 2003, 2:CD000440.
130. Reveley MA, Libretto SE: Treatment outcome in patients with chronic schizophrenia during long-term administration with risperidone. J Clin Psychopharmacol 2004, 24:260-267.

131. Parellada E: Long-acting injectable risperidone in the treatment of schizophrenia in special patient populations. Psychopharmacol Bull 2007 40:82-100.

132. Gilmer TP, Dolder CR, Lacro JP, Folsom DP, Lindamer L, Garcia P, Jeste DV: Adherence to treatment with antipsychotic medication and health care costs among Medicaid beneficiaries with schizophrenia. Am J Psychiatry 2004, 161:692-699.

133. Almerie MQ, Alkhateeb $\mathrm{H}$, Essali A, Matar HE, Rezk E: Cessation of medication for people with schizophrenia already stable on chlorpromazine. Cochrane Database Syst Rev 2007, 1:CD006329.

134. Sutton DL: Relapse signatures and insight: implications for CPNs. J Psychiatr Ment Health Nurs 2004, 11:569-574.

135. Larsen TK, Melle I, Friis S, Joa I, Johannessen JO, Opjordsmoen S, Simonsen E, Vaglum P, McGlashan TH: One-year effect of changing duration of untreated psychosis in a single catchment area. Br J Psychiatry Supp/ 2007, 51:s128-s132.

136. Tiihonen J, Haukka J, Taylor M, Haddad PM, Patel MX, Korhonen P: A nationwide cohort study of oral and depot antipsychotics after first hospitalization for schizophrenia. Am J Psychiatry 2011, 168:603-609.

137. Leucht S, Corves C, Arbter D, Engel RR, Li C, Davis JM: Second-generation versus first-generation antipsychotic drugs for schizophrenia: a metaanalysis. Lancet 2009, 373:31-41.

138. Leucht C, Heres S, Kane JM, Kissling W, Davis JM, Leucht S: Oral versus depot antipsychotic drugs for schizophrenia-a critical systematic review and meta-analysis of randomised long-term trials. Schizophrenia Res 2011, 127:83-92.

139. Leucht S, Tardy M, Komossa K, Heres S, Kissling W, Salanti G, Davis JM: Antipsychotic drugs versus placebo for relapse prevention in schizophrenia: a systematic review and meta-analysis. Lancet 2012, 379:2063-2071.

140. Kishimoto T, Robenzadeh A, Leucht C, Leucht S, Watanabe K, Mimura M, Borenstein M, Kane JM, Correll CU: Long-acting injectable vs oral antipsychotics for relapse prevention in schizophrenia: a meta-analysis of randomized trials. Schizophrenia Bull 2013. doi:10.1093/schbul/sbs150.

141. Kishimoto T, Masahiro N, Borenstein M: Poster Presented at ACNP: 2012 December 2-6. Florida, USA. poster number 175

doi:10.1186/1744-859X-12-32

Cite this article as: Olivares et al:: Definitions and drivers of relapse in patients with schizophrenia: a systematic literature review. Annals of General Psychiatry 2013 12:32

\section{Submit your next manuscript to BioMed Central and take full advantage of:}

- Convenient online submission

- Thorough peer review

- No space constraints or color figure charges

- Immediate publication on acceptance

- Inclusion in PubMed, CAS, Scopus and Google Scholar

- Research which is freely available for redistribution 